University of Montana

ScholarWorks at University of Montana

8-2007

\title{
Selection for Rapid Embryo Development Correlates with Embryo Exposure to Maternal Androgens Among Passerine Birds
}

\author{
Hubert Schwabl \\ Maria G. Palacios \\ Thomas E. Martin \\ University of Montana - Missoula, tom.martin@umontana.edu
}

Follow this and additional works at: https://scholarworks.umt.edu/wildbio_pubs

Part of the Life Sciences Commons

Let us know how access to this document benefits you.

\section{Recommended Citation}

Schwabl, Hubert; Palacios, Maria G.; and Martin, Thomas E., "Selection for Rapid Embryo Development Correlates with Embryo Exposure to Maternal Androgens Among Passerine Birds" (2007). Wildlife Biology Faculty Publications. 27.

https://scholarworks.umt.edu/wildbio_pubs/27

This Article is brought to you for free and open access by the Wildlife Biology at ScholarWorks at University of Montana. It has been accepted for inclusion in Wildlife Biology Faculty Publications by an authorized administrator of ScholarWorks at University of Montana. For more information, please contact scholarworks@mso.umt.edu. 


\title{
Selection for Rapid Embryo Development Correlates with Embryo Exposure to Maternal Androgens among Passerine Birds
}

\author{
Hubert Schwabl, ${ }^{1, *}$ Maria G. Palacios, ${ }^{2, \dagger}$ and Thomas E. Martin ${ }^{2, \ddagger}$
}

1. Center for Reproductive Biology, School of Biological Sciences, Washington State University, Pullman, Washington 99164;

2. United States Geological Survey, Montana Cooperative Wildlife Research Unit, University of Montana, Missoula, Montana 59812

Submitted August 30, 2006; Accepted February 28, 2007;

Electronically published June 27, 2007

ABSTRACT: Greater offspring predation favors evolution of faster development among species. We hypothesized that greater offspring predation exerts selection on mothers to increase levels of anabolic androgens in egg yolks to achieve faster development. Here, we tested whether (1) concentrations of yolk androgens in passerine species were associated with offspring predation and (2) embryo and nestling development rates were associated with yolk androgen concentrations. We examined three androgens that increase in potency along the synthesis pathway: androstenedione $\left(\mathrm{A}_{4}\right)$ to testosterone $(\mathrm{T})$ to $5 \alpha$-dihydrotestosterone ( $5 \alpha$-DHT). Concentrations of none of these steroids were related to clutch size; only $\mathrm{A}_{4}$ was allometrically related to egg volume. Species that experience greater predation showed higher yolk concentrations of T and $5 \alpha$-DHT. Higher concentrations of T and particularly $5 \alpha$-DHT were strongly correlated with faster development during the embryo period and less so during the nestling period. Development rates were most strongly correlated with $5 \alpha$-DHT, suggesting that potency increases along the androgen synthesis pathway and that effects are mediated by the androgen receptor pathway. These results are consistent with the hypothesis that selection for faster development by time-dependent offspring mortality may be achieved epigenetically by varying embryo exposure to maternal anabolic steroids.

Keywords: yolk steroids, allometry, development, nest predation, maternal effect, epigenetic.

\footnotetext{
* E-mail: huschwabl@wsu.edu.

† Present address: Department of Ecology, Evolution and Organismal Biology, Iowa State University, Ames, Iowa 50011; e-mail: mgp@iastate.edu.

‡ E-mail: tom.martin@umontana.edu.
}

Am. Nat. 2007. Vol. 170, pp. 196-206. (c) 2007 by The University of Chicago. 0003-0147/2007/17002-42047\$15.00. All rights reserved.
Development rates vary extensively among species, with faster development being favored in species experiencing greater offspring predation (Case 1978; Bosque and Bosque 1995; Martin 1995, 2002; Remeš and Martin 2002). The proximate physiological mechanisms underlying evolved variation in rate of development remain unclear, but variation in prenatal maternal contributions provides a likely possibility. Studies of maternal effects, where mothers alter nongenetic contributions to influence the phenotype of developing offspring (Mousseau and Fox 1998), and prenatal programming, the biomedical complement to maternal effects (e.g., Welberg and Seckl 2001; Bateson et al. 2004; Fleming et al. 2004), suggest that the environment, including the hormonal milieu, that the mother provides to the embryo and fetus affects their development. Both research arenas have focused on variation in maternal influences on offspring phenotypes within species. Yet the extent to which prenatal maternal effects vary among species in response to variation in selection pressures on the offspring (e.g., risk from disease and predation) has not been studied. Moreover, whether variation in prenatal maternal effects can explain interspecific variation in rate and duration of development is unresolved (see below). We postulate that differential selection from offspring predation favors variation in maternal biosynthesis and deposition of androgens into the yolks of vertebrate eggs to thereby explain interspecific variation in development rate.

Steroid hormones are integral regulatory signals in the cascade of the programmed processes of development and differentiation that leads from gene expression to phenotype (Arnold 2002). Historically, development has been viewed as a tightly integrated program and a relatively immutable life-history trait that is not regulated but may be perturbed by environmental input, such as maternal hormones (Gilbert 2001). Consequently, studies have mainly focused on the role of endogenous estrogens and androgens of embryonic and fetal origin in sexual differentiation (Arnold 2002), and effects of exogenous steroids, 
such as those of maternal origin, were considered to represent pathological perturbations of these genetic programs (Fleming et al. 2004). The discovery of systematic variation of androgenic steroids of maternal origin in avian eggs challenged this dogma and suggested that mothers may be able to adaptively modify development and differentiation by supplementing the embryo with these hormones (Schwabl 1993).

Avian eggs contain several maternally produced steroid hormones (e.g., Schwabl 1993, 1997; Hayward and Wingfield 2004; Groothuis et al. 2005). Androgenic steroids vary in their concentrations both within and among species (e.g., Schwabl 1993, 1997; Gil et al. 1999, 2007; Lipar et al. 1999; Gorman and Williams 2005; Groothuis et al. 2005), and increased levels can increase embryonic and posthatching development rates within species (e.g., Schwabl 1996; Eising et al. 2001; Navara et al. 2005; Tschirren et al. 2005; but see Sockman and Schwabl 2000 and von Engelhardt et al. 2006 for a delay of hatching). We examine whether nest predation exerts selection on mothers to deposit increased androgen concentrations in egg yolks as a proximate mechanism to increase development rates among species experiencing greater nest predation risk.

The possible role of nest predation on variation in androgen concentrations remains unexamined. However, the influence of yolk androstenedione $\left(\mathrm{A}_{4}\right)$ and testosterone (T) concentrations on interspecific variation in developmental rates has been explored in two recent comparative analyses. One analysis of 11 passerine bird species revealed robust negative correlations of embryo and nestling periods with yolk $\mathrm{T}$ concentrations for both raw data and phylogenetically independent contrasts, suggesting correlated evolution of yolk androgen deposition and development (Gorman and Williams 2005). A subsequent study of a larger sample of passerines revealed a significant negative relationship of overall duration of development period (embryo plus nestling periods) with yolk T concentrations that was, however, lost after correction for phylogeny (Gil et al. 2007). The discrepancy between these two analyses creates uncertainty over the role of interspecific variation in yolk androgens in development rates and highlights the need for further exploration of this unresolved issue.

Relationships may have been weakened or obscured by methodological artifacts related to use of hormone data derived from differing methods and laboratories and use of data on development rates from populations other than those from which hormones were sampled. Here, we minimized these possible sources of error by (1) using only hormone measurements that were obtained with a single method (Schwabl 1993), (2) assaying hormones in a single laboratory for the vast majority of species, and (3) using data on development rates from the same population from which hormone measurements were obtained for most species.

Another possible influence on prior results centers on questions about the specific androgens and biosynthetic pathways of greatest importance in influencing development. The prior analyses were limited to $\mathrm{T}$ and/or $\mathrm{A}_{4}$ and did not consider $5 \alpha$-dihydrotestosterone ( $5 \alpha$-DHT). Potency increases from $\mathrm{A}_{4}$ to $\mathrm{T}$ to $5 \alpha$-DHT along the androgen synthesis pathway (Harding 1998; Hiipakka and Liao 1998; Chen et al. 2004; Jasuja et al. 2005; Sonneveld et al. 2005, 2006). If the androgen receptor pathway is of greatest influence on development rates, then we expect $5 \alpha$-DHT to have the largest effect, and attention to only $\mathrm{A}_{4}$ and $\mathrm{T}$ may yield weaker relationships. On the other hand, $\mathrm{A}_{4}$ and $\mathrm{T}$ can be converted into estrogens (Payne and Hales 2004) and therefore can potentially act through the estrogen receptor pathway. In this case, potency and effect on development rates may be greatest for $\mathrm{T}$ and $\mathrm{A}_{4}$, while $5 \alpha$-DHT, which cannot be metabolized into estrogens (Payne and Hales 2004), would show no relationship with development rate. Thus, examination of all three androgens can allow determination of their relative importance and potency in affecting development rates and allow us to discern molecular pathways (i.e., androgen vs. estrogen receptor) by which yolk androgens might affect development.

We examined four predictions. (1) Increased risk of nest predation, an ultimate selection pressure, is associated with increased concentrations of maternally deposited yolk androgens. (2) Increased yolk androgen concentrations are associated with faster development, that is, the proximate mechanism. (3) Effects of yolk androgen concentrations on development rate increase up the androgen synthesis pathway, with the most potent androgen metabolite, $5 \alpha$ DHT, having the largest effect. Alternatively, if androgens act on development rates through the estrogen receptor pathway, other androgens $\left(\mathrm{A}_{4}, \mathrm{~T}\right)$ have larger effects on development rate (see above). (4) Androgen effects are stronger in the embryo period than in the postnatal period because the embryo assimilates most of the steroid-laced yolk before hatching (Romanoff 1944) and because predation rates are commonly higher during incubation than during nestling stages among north-temperate passerines (Martin 1992; Martin et al. 2000).

\section{Methods}

\section{Study Species}

We restricted this analysis to the order Passeriformes (i.e., songbirds) to minimize extended variation in possible confounding factors, such as phylogeny and development mode (all songbirds are altricial), while still retaining ex- 
tensive variation in developmental phenotypes. To avoid inherent variation in hormone measurements due to differing extraction and sample cleanup methods and use of antibodies with differing cross-reactivities with known and unknown steroids in yolk, we used only data in which yolk hormones were measured with the same protocol and antibodies (Schwabl 1993). Data are from wild populations breeding at middle northern latitudes in North America and Europe, except for two species (domestic canary and zebra finch). We used clutch means of androgens of 25 songbird species belonging to 12 families (table 1).

\section{Reproductive and Developmental Traits}

The 25 passerines varied extensively in embryo period (from 11.13 to 19.5 days), nestling period (from 8.35 to 28.4 days), nestling growth rate $k$ (from 0.223 to 0.639 ), and daily predation rate (from 0.005 to 0.102 ), as well as in adult mass (from 7.8 to $177.5 \mathrm{~g}$ ), egg volume (from 1.01 to $7.42 \mathrm{~cm}^{3}$ ), and clutch size (from 3.36 to 8.53 eggs). Duration of the embryo period, the incubation period, was measured as the number of days from last egg laid to last egg hatched (Briskie and Sealy 1990; Martin 2002).

Table 1: Passerine species used in analyses

\begin{tabular}{|c|c|c|}
\hline Species & $\begin{array}{l}\text { Source population } \\
\text { (no. clutches) }\end{array}$ & Comments, ${ }^{a}$ references \\
\hline \multicolumn{3}{|l|}{ Tyrannidae: } \\
\hline Empidonax occidentalis & Arizona (5) & This article \\
\hline Sayornis phoebe & New York (4) & No $5 \alpha$-DHT; Hauber and Pilz 2003 \\
\hline \multicolumn{3}{|l|}{ Corvidae: } \\
\hline Pica hudsonia & Washington (5) & This article \\
\hline \multicolumn{3}{|l|}{ Hirundinidae: } \\
\hline Hirundo rustica & New York (20) & $\begin{array}{l}\text { R. J. Safran, K. M. Pilz, K. J. McGraw, S. M. Correa, and H. } \\
\text { Schwabl, unpublished manuscript }\end{array}$ \\
\hline Tachycineta bicolor & Wisconsin $(20)$ & Whittingham and Schwabl 2002 \\
\hline \multicolumn{3}{|l|}{ Paridae: } \\
\hline Parus major & Switzerland (54) & Tschirren et al. 2004 \\
\hline \multicolumn{3}{|l|}{ Troglodytidae: } \\
\hline Troglodytes aedon & Arizona (6) & This article \\
\hline \multicolumn{3}{|l|}{ Turdidae: } \\
\hline Catharus guttatus & Arizona (4) & This article \\
\hline Turdus migratorius & Arizona (5) & This article \\
\hline Turdus merula & Bavaria (31) & J. Partecke, E. Gwinner, and S. Bensch, unpublished manuscript \\
\hline Sialia sialis & Alabama (14) & No $5 \alpha$-DHT; GH; Navara et al. 2005 \\
\hline \multicolumn{3}{|l|}{ Sturnidae: } \\
\hline Sturnus vulgaris & Germany (14), Sweden (14) & Pilz et al. 2003; Gwinner and Schwabl 2005 \\
\hline \multicolumn{3}{|l|}{ Parulidae: } \\
\hline Vermivora virginiae & Arizona (4) & This article \\
\hline Vermivora celata & Arizona (1) & This article \\
\hline Dendroica petechia & New York (4) & No 5 $\alpha$-DHT; Hauber and Pilz 2003 \\
\hline Cardellina rubrifrons & Arizona (5) & This article \\
\hline \multicolumn{3}{|l|}{ Emberizidae: } \\
\hline Pipilo chlorurus & Arizona (2) & This article \\
\hline Junco hyemalis & Arizona (6) & This article \\
\hline Melospiza melodia & New York (2) & No $5 \alpha$-DHT; this article \\
\hline \multicolumn{3}{|l|}{ Icteridae: } \\
\hline Agelaius phoeniceus & Ohio (23) & EK; Lipar et al. 1999 \\
\hline Molothrus ater & New York (5) & No DMR; Hauber and Pilz 2003 \\
\hline \multicolumn{3}{|l|}{ Fringillidae: } \\
\hline Carpodacus mexicanus & Montana (15) & No $A_{4} ; \mathrm{GH} ;$ Badyaev et al. 2005 \\
\hline Serinus canaria & Domesticated (11) & No DMR; Schwabl 1993 \\
\hline \multicolumn{3}{|l|}{ Passeridae: } \\
\hline Poephila guttata & Domesticated (5) & No DMR; Schwabl 1993 \\
\hline Passer domesticus & Washington (55) & No DMR; Poopatanapong 2002 \\
\hline
\end{tabular}

${ }^{a}$ Comments note any missing data (e.g., "No $5 \alpha$-DHT"; DHT = dihydrotestosterone; $\mathrm{A}_{4}=$ androstenedione; DMR = daily mortality rate) and the assay labs $(\mathrm{GH}=$ Hill lab, EK $=$ Ketterson lab; all other hormone assays were done in the Schwabl lab). 
Duration of the nestling period was measured as the number of days from last egg hatched to last nestling to fledge. Nestling growth rate was measured as the slope, $k$, of the standard sigmoidal relationship (Remeš and Martin 2002). Egg size was calculated as egg volume from egg width and length, according to Hoyt (1979). Clutch size was the final number of eggs laid and observed without changing over 2 days after laying. Daily nest predation rates are the daily probabilities of nest contents (eggs and nestlings) being lost to predators and were estimated following Mayfield (1975) and Hensler and Nichols (1981). Whenever possible, we obtained estimates for reproductive and developmental traits and nest predation rates from the population for which yolk hormones were sampled.

\section{Yolk Steroid Measurements}

Yolk concentrations of $\mathrm{A}_{4}$, T, and $5 \alpha$-DHT of all species were measured according to the same protocol and with the same antibodies (Schwabl 1993). Hormone data for 22 of the 25 species were obtained in the Schwabl laboratory; data for three additional species were obtained with the same method and antibodies in two other laboratories (table 1). This stringent selection of hormone values avoids potential variation in hormone concentrations due to variation in extraction and separation procedures and crossreactivity of antibodies with other known and unknown steroids in yolk. All eggs were collected on the day they were laid and frozen until hormone analyses. Briefly, steroids were extracted from yolk homogenates with diethyl ether/petroleum ether, purified from lipids, separated by diatomaceous earth column chromatography, and measured using radioimmunoassay. Antibodies used were $\mathrm{T}$ 3003 (Wien Laboratories) for T and $5 \alpha$-DHT and A 1707 (Wien Laboratories) for $\mathrm{A}_{4}$. The ${ }^{3} \mathrm{H}$-labeled steroids NET $553(\mathrm{~T})$, NET 544 ( $5 \alpha$-DHT), and NET $469\left(\mathrm{~A}_{4}\right)$ were obtained from PerkinElmer Life and Analytical Sciences.

\section{Data Analyses}

We examined all variables for skew and kurtosis and log transformed all variables to meet normality assumptions, except the rate of nestling growth, $k$, which was normally distributed without transformation. We were interested in examining the relative strength of each of the three androgens in explaining variation in traits. However, because we examined three interdependent hormones, we first conducted a MANOVA with the three hormones as the dependent variables and the relevant covariates entered together in a global model to correct for experiment-wise error and interacting effects of covariates. This approach included only those species in which all three hormones were measured $(N=20 \mathrm{spp}$.). When a variable was sig- nificant under the multivariate analysis, then we examined it relative to the individual hormones through simple or partial correlation analysis to use the full set of species with data for each hormone (up to $25 \mathrm{spp}$.). In these latter cases, we applied a Bonferroni correction for multiple comparisons across the three hormones. Multiple-regression analyses to check the ability of multiple androgens to explain residual variation in developmental traits through partial correlations, or part correlations (residual variation in a hormone accounting for its precursor), always yielded $5 \alpha$-DHT alone as a significant partial or part correlate, and thus these analyses are not presented.

We repeated all analyses with Vermivora celata removed, because it was the one species with a sample size of one nest for androgen concentrations (table 1). Correlations did not change or very slightly increased in all cases, and significance of relationships did not change in any instance. We therefore left it in analyses because androgen concentrations were very similar to those of a closely related species with a larger sample size, Vermivora virginiae, which suggests that measured androgen concentrations in $V$. celata were reasonable, and because it was never an outlier data point.

We applied independent contrasts (Felsenstein 1985) using the "crunch" option of program CAIC 2.6.9 (Purvis and Rambaut 1995) and equal branch lengths to control for possible phylogenetic effects. The phylogeny was based on Sibley and Ahlquist (1990). Since the 25 studied species represent a diverse mix of 12 families, the phylogenetic effects were relatively minimal, and independent contrasts yielded effectively the same significance results as obtained with raw data in the vast majority of cases. However, there were a few differences, and so we report analyses for both raw data and independent contrasts in tables and raw data in figures.

\section{Results}

\section{Allometry, Egg Size, and Clutch Size}

We conducted a partial correlation analysis of egg volume relative to adult body mass and clutch size. Egg volume was strongly related to adult body mass (raw data: $r_{\mathrm{p}}$ [partial correlation coefficient] $=0.95, P<.0001, N=24$; independent contrast: $\left.r_{\mathrm{p}}=0.93, P<.0001, N=23\right)$ and negatively related to clutch size (raw data: $r_{\mathrm{p}}=-0.39$, $P=.067$; independent contrast: $r_{\mathrm{p}}=-0.40, P=.061$ ), as reported in other, broader analyses of passerine species (Martin et al. 2006). Yolk mass and egg volume also were strongly correlated $(r=0.974, P<.001$; subsample of species, $N=9$ ). Given these collinearities, we use only egg volume for allometric analyses hereafter.

We conducted a MANOVA of the three yolk androgens 
with egg volume and clutch size to examine possible allometric effects and found a significant effect of egg volume (Pillai's trace $=0.49, P=.022$ ) but not clutch size (Pillai's trace $=0.24, P=.27$ ). The nonsignificance of clutch size indicates that interspecific differences in concentrations of yolk androgens are not a simple consequence of the number of eggs that are simultaneously proliferated in the ovary. Egg volume was significant because of its relationship to yolk $\mathrm{A}_{4}(F=10.8, \mathrm{df}=1,18$, $P=.004)$ but not $\mathrm{T}(F=0.5, \mathrm{df}=1,18, P=.5)$ or $5 \alpha$ DHT $(F=0.2, \mathrm{df}=1,18, P=.7)$. Similar results were found when each hormone was analyzed separately to include all species with data for that hormone; T and $5 \alpha$ DHT were not significantly related to egg volume, while $\mathrm{A}_{4}$ was significantly related when corrected for phylogeny (table 2).

Finally, duration of embryo period also did not scale with egg volume (raw data: $r=0.12, P=.57, N=25$; independent contrast: $r=0.01, P=.95, N=24$ ), as observed previously for songbirds (Martin 2002). Allometric scaling thus does not explain variation in rate of embryo development or in yolk androgen concentrations among the passerine species that we studied, with the exception of a correlation of $\mathrm{A}_{4}$ concentrations with egg volume. In other words, yolk T and $5 \alpha$-DHT concentrations are not just a by-product of physiological processes associated with the proliferation of ovarian eggs.

\section{Variation and Correlation between Yolk Androgens}

Yolk $\mathrm{A}_{4}, \mathrm{~T}$, and $5 \alpha$-DHT varied 20-, 170-, and 20-fold, respectively, among the 25 species. This variation is much greater than that observed among females within species or within females with the order of laying (Groothuis et al. 2005). Although in the ovarian synthesis pathway $\mathrm{A}_{4}$ is an immediate precursor to $\mathrm{T}$, yolk $\mathrm{T}$ concentrations were only weakly correlated with yolk $\mathrm{A}_{4}$ concentrations (raw data: $r=0.30, P=.16, N=24$; independent contrast: $r=0.50, P=.013, N=23$; fig. 1$)$. In contrast, $5 \alpha-\mathrm{DHT}$

Table 2: Correlations of yolk androstenedione $\left(\mathrm{A}_{4}\right)$, testosterone (T), and $5 \alpha$-dihydrotestosterone ( $5 \alpha$-DHT) concentrations with egg volume $\left(\mathrm{cm}^{3}\right)$

\begin{tabular}{|c|c|c|c|c|c|c|}
\hline & \multicolumn{2}{|c|}{$\mathrm{A}_{4}(\mathrm{pg} / \mathrm{mg})$} & \multicolumn{2}{|c|}{$\mathrm{T}(\mathrm{pg} / \mathrm{mg})$} & \multicolumn{2}{|c|}{$\begin{array}{c}5 \alpha-\mathrm{DHT} \\
(\mathrm{pg} / \mathrm{mg})\end{array}$} \\
\hline & Raw & IC & Raw & $\overline{\mathrm{IC}}$ & Raw & IC \\
\hline$r$ & .44 & .48 & -.19 & .05 & -.10 & .02 \\
\hline$P$ & .033 & $.017^{\mathrm{a}}$ & .37 & .80 & .68 & .94 \\
\hline$N$ & 24 & 23 & 25 & 24 & 21 & 20 \\
\hline
\end{tabular}

Note: Correlations are based on raw data and phylogenetically corrected independent contrasts (IC).

${ }^{\text {a }}$ Relationship is significant, after Bonferroni correction for three comparisons.
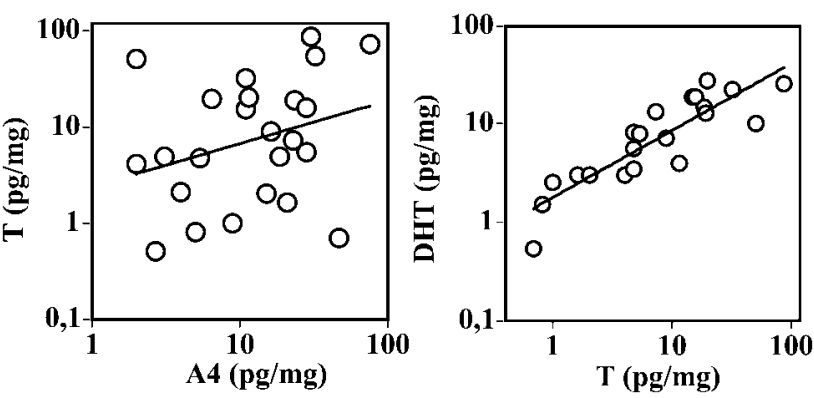

Figure 1: Correlation between concentrations of testosterone $(\mathrm{T})$ and androstenedione $\left(\mathrm{A}_{4}\right.$, left $)$ and between $5 \alpha$-dihydrotestosterone $(5 \alpha$ DHT) and T (right) in the yolks of eggs of passerine birds. Testosterone concentrations are not correlated with concentrations of its immediate synthesis precursor $\mathrm{A}_{4}$ for raw data but are correlated weakly for independent contrasts; $5 \alpha$-DHT concentrations are strongly positively correlated with concentrations of its immediate synthesis precursor $\mathrm{T}$ for both raw data and independent contrasts (see "Results" for statistics).

was strongly correlated with its immediate precursor $\mathrm{T}$ (raw data: $r=0.88, P<.001, N=21$; independent contrast: $r=0.88, P<.001, N=20$; fig. 1).

\section{Predation Rate}

Daily predation rates of nests were related to yolk androgen concentrations among species (MANOVA: Pillai's trace $=0.48, P=.041, N=16)$ because of significant relationships with yolk $\mathrm{T}(F=6.3, \mathrm{df}=1,14, P=.025)$ and $5 \alpha$-DHT $(F=5.0, \mathrm{df}=1,14, P=.043)$ but not $\mathrm{A}_{4}$ $(F=3.0, \mathrm{df}=1,14, P=.11)$. Similar results were found when hormones were analyzed separately to include all species with data for each hormone (fig. 2): concentrations of yolk $\mathrm{A}_{4}$ were not related to daily predation rate (raw data: $r=0.15, P=.54, N=20$; independent contrast: $r=0.15, P=.52, N=19$ ), while concentrations of yolk $\mathrm{T}$ were positively correlated with daily predation rate (raw data: $r=0.71, P<.001, N=21$; independent contrast: $r=0.51, P=.017, N=20$ ). Concentrations of $5 \alpha-\mathrm{DHT}$ were positively correlated with daily predation rate for raw data but were only marginally significant for independent contrasts (raw data: $r=0.51, P=.037, N=17$; independent contrast: $r=0.45, P=.067, N=16)$. The marginal significance of independent contrasts for $5 \alpha$-DHT reflected a strong effect of the contrast at the root node, which was the contrast between Empidonax occidentalis, a suboscine, and the rest of the tree of oscines; exclusion of this contrast yielded a significant relationship between $5 \alpha$ DHT and predation rate even when corrected for phylogeny (raw data: $r=0.62, P=.010, N=16$; independent contrast: $r=0.51, P=.037, N=15)$. 

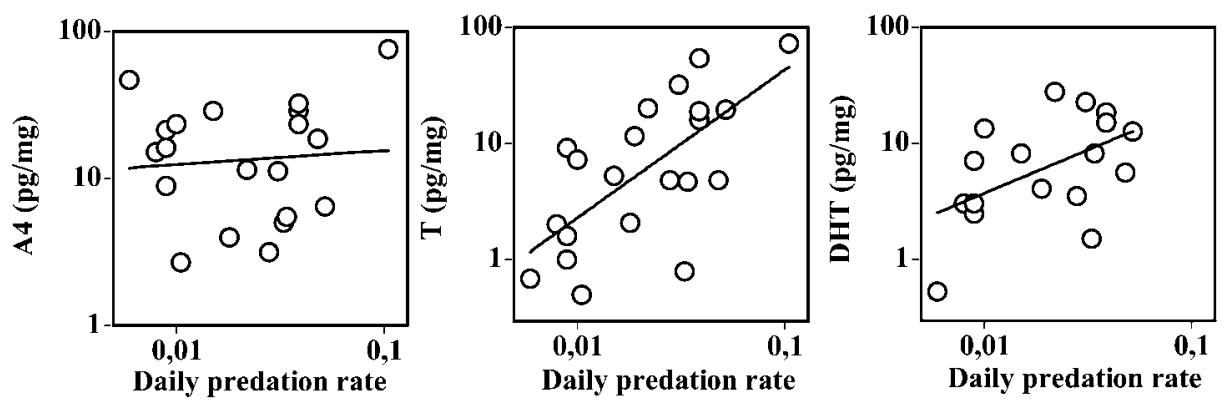

Figure 2: Androgen concentrations in the yolk of passerine bird eggs in relation to daily predation rate (probability of predation per day) of eggs and nestlings. Yolk androstenedione $\left(\mathrm{A}_{4}\right)$ is not correlated with daily predation rate for raw data and independent contrast. Yolk testosterone $(\mathrm{T})$ is correlated with predation rate for both raw data and independent contrasts. Yolk $5 \alpha$-dihydrotestosterone (DHT) is correlated with daily predation rate for raw data of all species and for independent contrasts when the contrast at the root node, which is the contrast between Empidonax occidentalis and the rest of the tree, is removed (see "Results").

\section{Embryo and Nestling Development}

Yolk androgen concentrations were related to duration of the embryo period (MANOVA: Pillai's trace $=0.43$, $P=.044, N=20$ ) but not the nestling period (Pillai's trace $=0.22, P=.32$ ) or nestling growth rate (Pillai's trace $=0.31, P=.14)$. The relationship with embryo period was most strongly influenced by $5 \alpha$-DHT $(F=$ 33.3, $\mathrm{df}=1,18, P<.001)$ and also $\mathrm{T}(F=13.6, \mathrm{df}=$ $1,18, P=.002)$ but not $\mathrm{A}_{4}(F=0.1, \mathrm{df}=1,18, P=.7)$. These results, as well as correlations of the individual yolk androgens for all species with data on each hormone (table $3 A$ ), showed two interesting patterns. First, strength of correlations increased with androgenic potency from $\mathrm{A}_{4}$ to $\mathrm{T}$ to $5 \alpha$-DHT (table $3 A$; see also $F$ values above). Second, concentrations of androgens were most strongly correlated with embryo development, although nestling period showed individual but weaker correlations (table 3A; fig. 3). The higher correlations of embryo period thereby caused nestling period and growth rate to lack significance in relationship to androgen concentrations in the global model (see above).

One species, Pica hudsonia, was a strong outlier in all relationships (see fig. 3). Removal of this species yielded the same basic results: yolk androgen concentrations were related to duration of the embryo period (MANOVA: Pillai's trace $=0.45, P=.043, N=19)$ but not the nestling period (Pillai's trace $=0.30, P=.19$ ) or nestling growth rate (Pillai's trace $=0.28, P=.22$ ). The relationship with embryo period remained most strongly influenced by $5 \alpha$ DHT $(F=15.9, \mathrm{df}=1,17, P=.001)$ and was also influenced by $\mathrm{T}(F=9.2, \mathrm{df}=1,17, P=.008)$ but not $\mathrm{A}_{4}$ $(F=2.0, \mathrm{df}=1,17, P=.17)$. Exclusion of this species also caused a reduction in the strength of correlations of $\mathrm{T}$ and $5 \alpha$-DHT with the nestling period, which became largely nonsignificant when Bonferroni adjustments were taken into account, and the emergence of a significant relationship of $\mathrm{A}_{4}$ and embryo period (table $3 B$ ). Thus, without this species, nestling development parameters were poorly related to androgen concentrations, whereas embryo period was the only trait that was related to all three androgens, again emphasizing that relationships were strongest during the embryo period.

\section{Discussion}

Selection on offspring to develop faster and reduce exposure to time-dependent mortality caused by predation is well documented (Case 1978; Bosque and Bosque 1995; Martin 2002; Remeš and Martin 2002). Our results with passerine birds demonstrate that faster development, particularly of the embryo, favored by natural selection via time-dependent offspring predation, is correlated with higher yolk concentrations of T and particularly $5 \alpha$-DHT. These results are consistent with those of a previous study of passerines reporting a negative correlation of embryo and nestling periods with yolk T (Gorman and Williams 2005). Our results are also qualitatively similar to those of Gil et al. (2007), who found weaker relationships with T. Our stronger results might reflect our attempt to more stringently control extraneous variation by restricting our analyses to species in which yolk androgens were measured using the same method and, whenever possible, by using developmental rates from the same populations from which yolk hormone measurements were obtained. Our results also advance understanding by showing, for the first time, that (1) development rate is most strongly associated with the most potent vertebrate androgen, $5 \alpha$ DHT (Harding 1998; Hiipakka and Liao 1998; Sonneveld et al. 2005, 2006), thereby also implicating the androgen receptor pathway as most important in influencing de- 
Table 3: Simple correlations of three developmental traits (embryo period, nestling period, and nestling growth rate) with yolk androgen concentrations

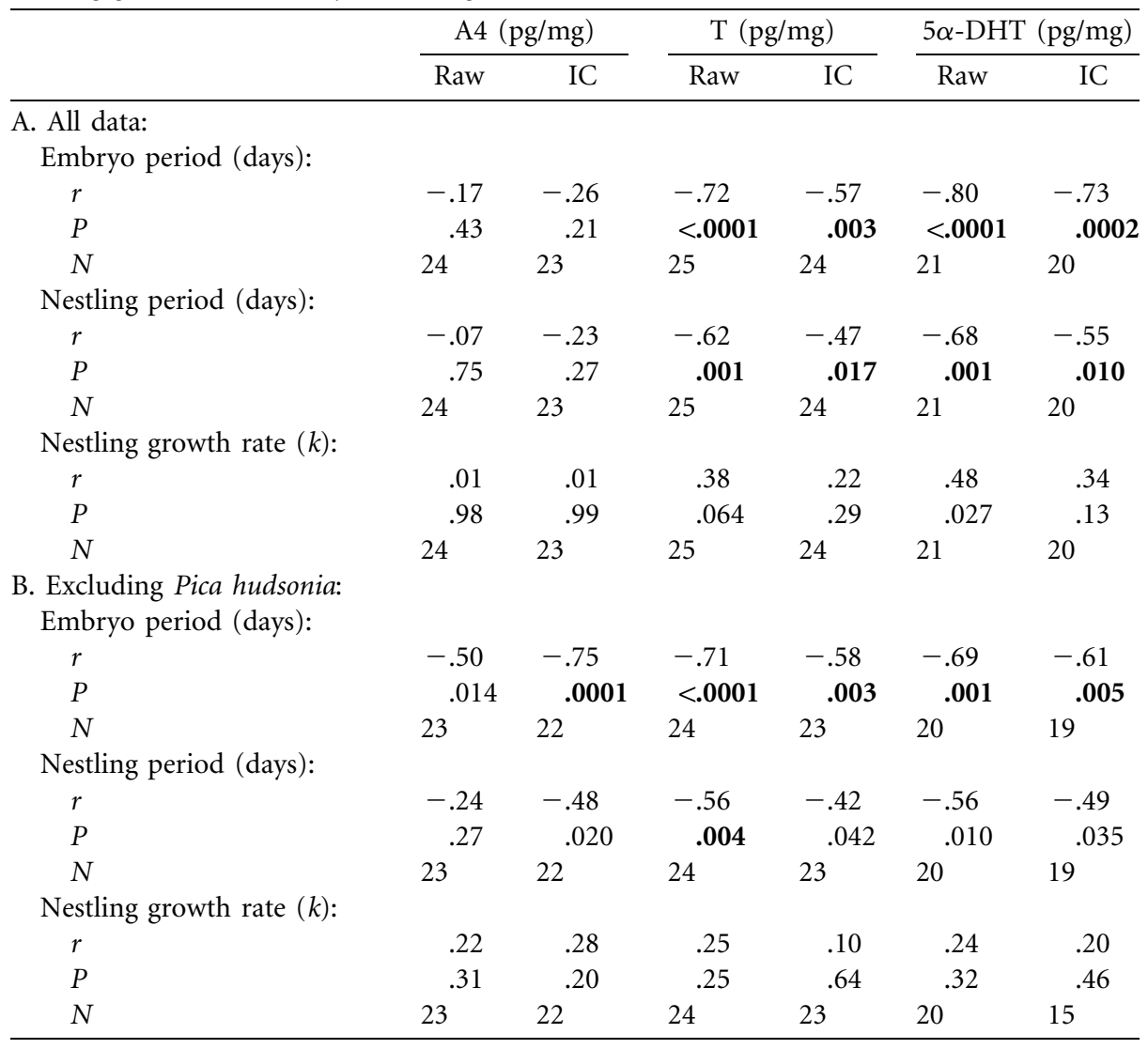

Note: Correlations are based on raw data and phylogenetically corrected independent contrasts (IC) for all data $(A)$ and excluding the outlier Pica hudsonia (B). Significant relationships, after Bonferroni correction for multiple comparisons (three hormone tests per developmental trait for all data and six tests for the added comparison without $P$. hudsonia), are in boldface.

velopment rates; (2) correlations with maternal androgens are stronger for embryo than for nestling stages; and (3) $\mathrm{T}$ and $5 \alpha$-DHT are highest in species experiencing the greatest nest predation rates.

Allometry and clutch size did not explain interspecific variation in yolk androgen concentrations, except for a positive relationship of $\mathrm{A}_{4}$ with egg volume. Thus, we argue that interspecific variation of yolk T and $5 \alpha$-DHT concentrations is not the product of differences in magnitude of ovarian steroid synthesis associated with the number or size of eggs that are simultaneously proliferated in the ovary, previously proposed to explain intraspecific variation of yolk testosterone with laying order (Schwabl 1993). Instead, we argue that interspecific variation in concentrations of yolk T and $5 \alpha$-DHT is associated with timedependent embryo and nestling mortality by predation and its selection on development rates.

Yolk T and $5 \alpha$-DHT concentrations were positively correlated with daily offspring predation rates. In turn, embryo and, to a lesser extent, nestling periods were nega- tively correlated with yolk T and DHT concentration, while nestling growth rate was not. Androgen concentrations were more strongly associated with developmental rate in the embryo stage than in the nestling stage. These results are consistent with strong maternal androgenic effects on rate of embryo development but reduced effects on development rate of nestlings. This is not surprising, for the following proximate and ultimate reasons. First, the embryo consumes most of the androgen-laced yolk, while the nestling is exposed to yolk hormones only for a brief period after hatching that may last for 1-2 days, when it consumes "spare yolk" (Romanoff 1944). Second, predation rates are commonly higher during incubation than during nestling stages among north-temperate passerine species (Martin 1992; Martin et al. 2000), suggesting that selection should be acting most stringently during the embryo phase. Third, hormonal effects on nestlings may be swamped by additional influences on their development rates, such as parental feeding rates. Effects of yolk androgens on nestling growth shown in previous intraspecific 

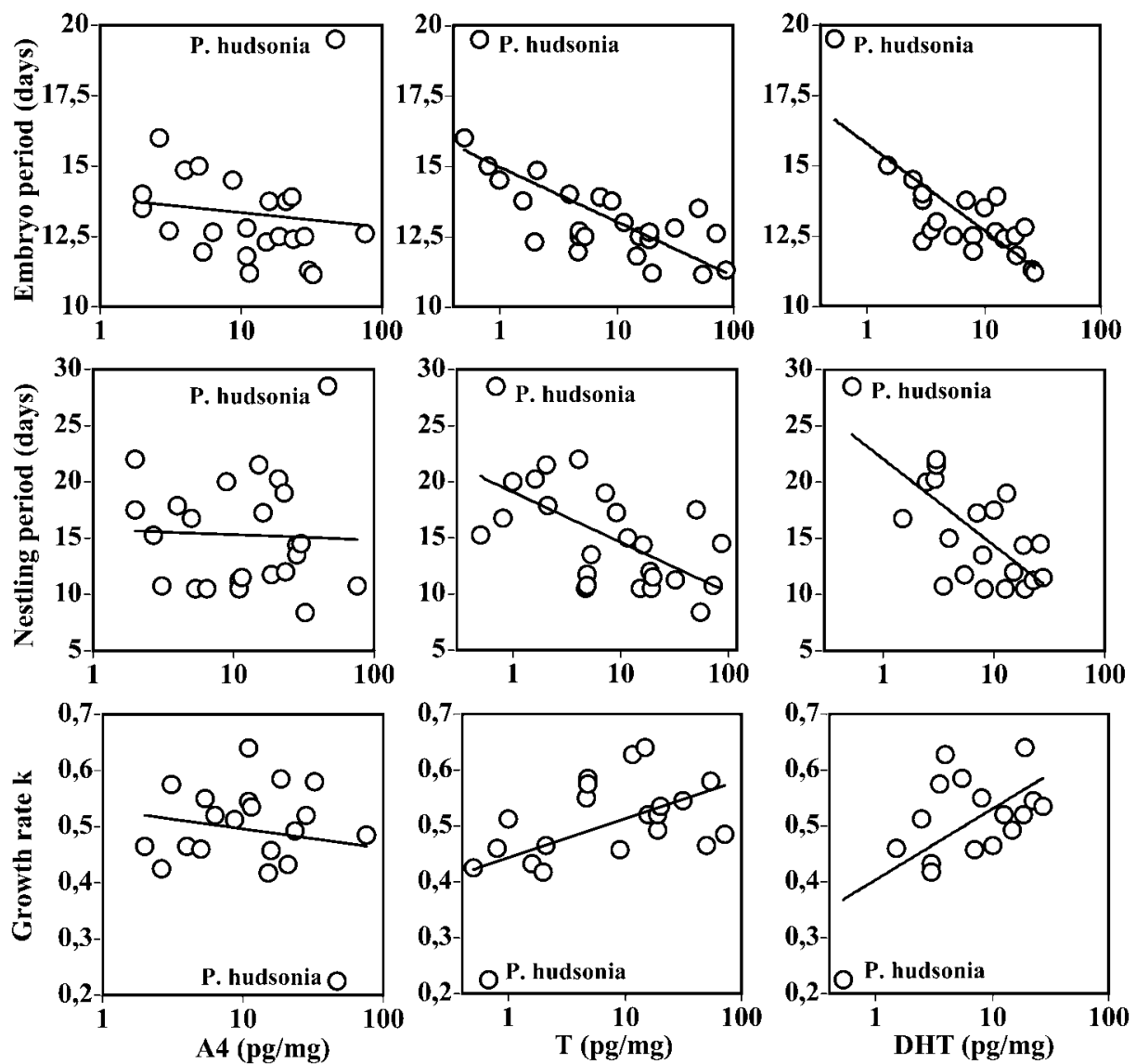

Figure 3: Development parameters of passerine bird species in relation to the concentrations of androstenedione $\left(\mathrm{A}_{4}\right.$; left), testosterone $(\mathrm{T} ;$ middle), and $5 \alpha$-dihydrotestosterone ( $5 \alpha$-DHT; right) in the yolks of their eggs. Duration of the embryo period (top), duration of the nestling period (middle), and nestling growth rate $k$ (bottom) are correlated with yolk T and $5 \alpha$-DHT, while they are not correlated with yolk $\mathrm{A}_{4}$ concentrations. Values for Pica hudsonia, an outlier, are indicated in plots. See table 3 for statistics.

studies (e.g., Schwabl 1996; Navara et al. 2005; Tschirren et al. 2005; von Engelhardt et al. 2006) might thus reflect carryover of actions on the embryo.

The robust association of embryo period with yolk $5 \alpha$ DHT, which cannot be converted into estrogens, has the greatest affinity for the androgen receptor, and is the biologically most potent androgen, suggests that effects are mediated by the androgen receptor pathway. Androstenedione can also activate the androgen receptor (Holterhus et al. 2002; Chen et al. 2004; Jasuja et al. 2005), but it has a low affinity for the androgen receptor $(0.1 \%$ that of $5 \alpha$ DHT) and a relatively low biological activity in vivo. For example, the relative agonistic activity of $\mathrm{A}_{4}$ in cell-linebased in vivo assays is $5.7 \%$ that of $5 \alpha$-DHT, while that of $\mathrm{T}$ is $14.6 \%$ that of $5 \alpha$-DHT (Sonneveld et al. 2005, 2006). Since $\mathrm{A}_{4}, \mathrm{~T}$, and $5 \alpha$-DHT can activate the androgen receptor and induce different gene expression patterns (Holterhus et al. 2002), their effects on development might differ as well. Alternatively, yolk $\mathrm{A}_{4}$ and $\mathrm{T}$ could act through the estrogen receptor after being aromatized to estrogens by embryonic tissue (Payne and Hales 2004), possibly providing another pathway to influence embryo development. Moreover, $\mathrm{A}_{4}$ may serve as a precursor for $\mathrm{T}$ in the embryo, thereby contributing to the pool of biologically potent androgens (Groothuis and Schwabl 2002; Gil et al. 2007). In the end, $A_{4}$ was not strongly correlated with development rates, and the strong correlation of $5 \alpha$ DHT with embryo development rate suggests a key role of the androgenic pathway. Ultimately, examination of these alternative mechanistic pathways may provide greater insight into developmental responses.

Despite these unanswered mechanistic questions, our results provide robust evidence for an evolutionary response in a maternal trait (i.e., maternal synthesis and/or deposition of androgens into eggs during egg formation) to selection (i.e., mortality by nest predation) on offspring 
development traits (i.e., rate and duration of development). In short, our results suggest that time-dependent mortality may favor greater concentrations of maternally produced T and $5 \alpha$-DHT in egg yolks to provide an evolved epigenetic maternal mechanism to speed up offspring development. The biosynthesis pathway for these three hormones is quite simple and thus may easily respond to selection: $T$ is produced from $A_{4}$ by $17 \beta-$ hydroxysteroid-dehydrogenase, and $5 \alpha$-DHT is produced from T by $5 \alpha$-reductase (Johnson 2000; Payne and Hales 2004). Both conversions are single-step enzymatic reactions that likely reflect single-gene control and therefore may respond easily to natural selection on embryo development rate.

Females could shorten the duration of development periods through other mechanisms, such as maintaining higher embryonic temperatures through increased incubation effort (Martin 2002) and enhancing nestling growth by increased food provisioning. However, such strategies likely increase energetic costs and mortality risk of the parents (Martin 2002; Remeš and Martin 2002). Enhancing development rate by increasing the concentrations of development- and maturation-promoting androgens in the eggs before they are laid may provide a means to avoid these parental costs and thus can represent a critical female strategy that has gone unappreciated.

On the other hand, selection on androgen concentrations in eggs may be constrained by their possible pleiotropic effects. Indeed, variation, rather than maximization, in this epigenetic hormonal mechanism may arise because of several potential physiological trade-offs that are not mutually exclusive. First, androgens regulate female reproductive functions (e.g., Staub and DeBeer 1997; Ketterson et al. 2005), and so the production of androgens for yolks may interfere with regulatory functions of these hormones in the female. Second, steroid-enhanced fast early growth may compromise life span through physiological trade-offs (Metcalfe and Monaghan 2003), and early androgen exposure can affect immune function (Müller et al. 2005). Third, developmental androgen exposure can permanently alter the physiological and behavioral phenotype over a lifetime. For example, neuroendocrine systems, such as the brain-pituitary-adrenal axis, whose hormones mediate behavioral and physiological responses to environmental conditions and stress, are altered by developmental exposure to maternal steroids (e.g., McCormick et al. 1998; Schwabl 1999; Sockman and Schwabl 2001; Welberg and Seckl 2001), and yolk androgens permanently alter behavior (Strasser and Schwabl 2004; Eising et al. 2006). Such effects likely exert fitness consequences that must be balanced against the fitness benefits yielded by fast early growth. In the end, examination of the physiological mechanisms (e.g., biosynthesis pathways and androgen deposition in eggs; receptor pathways in the embryo) underlying variation in life-history traits (e.g., development rates) is a key step in advancing understanding of life-history evolution.

\section{Acknowledgments}

We are grateful to K. Pilz and M. Hauber for providing unpublished data on yolk steroids and to A. Badyaev, K. Sockman, M. Webster, the ABC discussion group, and anonymous reviewers for comments on earlier versions of this article. Our work was supported by the National Science Foundation (grants IBN-9604370 to H.S. and DEB9981527 and DEB-0543178 to T.E.M.), the National Institutes of Health (grant MH 4987 to H.S.), the Harry Frank Guggenheim Foundation (H.S.), the Global Climate Change Program of the United States Geological Survey (T.E.M.), and the National Research Initiative of the United States Department of Agriculture Cooperative State Research, Education and Extension Service (grant 200502817 to T.E.M.).

\section{Literature Cited}

Arnold, A. P. 2002. Concepts of genetic and hormonal induction of vertebrate sexual differentiation in the twentieth century, with special reference to the brain. Pages 105-135 in D. Pfaff, A. Arnold, A. Etgen, S. Fahrbach, and R. Rubin, eds. Hormones, brain, and behavior. Vol. 4. Academic Press, New York.

Badyaev, A. V., H. Schwabl, R. L. Young, R. A. Duckworth, K. Navara, and A. F. Parlow. 2005. Adaptive sex differences in growth of preovulation oocytes in a passerine bird. Proceedings of the Royal Society B: Biological Sciences 272:2165-2172.

Bateson, P., D. Barker, T. Clutton-Brock, D. Deb, B. D’Udine, R. A. Foley, P. Gluckman, et al. 2004. Developmental plasticity and human health. Nature 430:419-421.

Bosque, C., and M. T. Bosque. 1995. Nest predation as a selective factor in the evolution of developmental rates in altricial birds. American Naturalist 145:234-260.

Briskie, J. V., and S. G. Sealy. 1990. Evolution of short incubation periods in the parasitic cowbirds, Molothrus spp. Auk 107:789794.

Case, T. J. 1978. On the evolution and adaptive significance of postnatal growth rates in terrestrial vertebrates. Quarterly Reviews in Biology 53:243-282.

Chen, F., K. Knecht, C. Leu, S. J. Rutledge, A. Scafonas, C. Gambone, R. Vogel, et al. 2004. Partial agonist/antagonist properties of androstenedione and 4 -androsten-3 $\beta, 17 \beta$-diol. Journal of Steroid Biochemistry and Molecular Biology 91:247-257.

Eising, C. M., C. Eikenaar, H. Schwabl, and T. G. G. Groothuis. 2001. Maternal androgens in black-headed gull (Larus ridibundus) eggs: consequences for chick development. Proceedings of the Royal Society B: Biological Sciences 268:839-846.

Eising, C. M., W. Müller, and T. G. G. Groothuis. 2006. Avian mothers create different phenotypes by hormone deposition in their eggs. Biology Letters 2:20-22.

Felsenstein, J. 1985. Phylogenies and the comparative method. American Naturalist 125:1-15. 
Fleming, T. P., W. Y. Kwong, R. Porter, E. Ursell, I. Fesenko, A. Wilkins, D. J. Miller, A. J. Watson, and J. J. Eckert. 2004. The embryo and its future. Biology of Reproduction 71:1046-1054.

Gil, D., J. Graves, N. Hazon, and A. Wells. 1999. Male attractiveness and differential testosterone investment in zebra finch eggs. Science 286:126-128.

Gil, D., C. Biard, A. Lacroix, C. Spottiswoode, N. Saino, M. Puerta, and A. P. Møller. 2007. Evolution of yolk androgens in birds: development, coloniality, and sexual dichromatism. American Naturalist 169:802-819.

Gilbert, S. F. 2001. Ecological developmental biology: developmental biology meets the real world. Developmental Biology 233:1-12.

Gorman, K. B., and T. D. Williams. 2005. Correlated evolution of maternally derived yolk testosterone and early developmental traits in passerine birds. Biology Letters 1:461-464.

Groothuis, T. G., and H. Schwabl. 2002. Determinants of withinand among-clutch variation in levels of maternal hormones in black-headed gull eggs. Functional Ecology 16:281-289.

Groothuis, T. G. G., W. Müller, N. von Engelhardt, C. Carere, and C. Eising. 2005. Maternal hormones as a tool to adjust offspring phenotype in avian species. Neuroscience and Biobehavioral Reviews 29:329-352.

Gwinner, H., and H. Schwabl. 2005. Evidence for sexy sons in European starlings (Sturnus vulgaris). Behavioral Ecology and Sociobiology 58:375-382.

Harding, C. 1998. Androgens, effects in birds. Pages 188-196 in E. Knobil and J. D. Neill, eds. Encyclopedia of reproduction. Vol. 1. Academic Press, San Diego, CA.

Hauber, M. E., and K. M. Pilz. 2003. Yolk testosterone levels are not consistently higher in the egg of obligate brood parasites than their hosts. American Midland Naturalist 149:354-362.

Hayward, L. S., and J. C. Wingfield. 2004. Maternal corticosterone is transferred to avian yolk and may alter offspring growth and adult phenotype. General and Comparative Endocrinology 135: 365-371.

Hensler, G. L., and J. D. Nichols. 1981. The Mayfield method of estimating nesting success: a model, estimators and simulation results. Wilson Bulletin 93:42-53.

Hiipakka, R. A., and S. Liao. 1998. Dihydrotestosterone. Pages 872879 in E. Knobil and J. D. Neill, eds. Encyclopedia of reproduction. Vol. 1. Academic Press, San Diego, CA.

Holterhus, P. M., S. Piefke, and O. Hiort. 2002. Anabolic steroids, testosterone-precursors and virilizing androgens induce distinct activation profiles of androgen responsive promoter constructs. Journal of Steroid Biochemistry and Molecular Biology 82:269275.

Hoyt, D. F. 1979. Practical methods of estimating volume and fresh weight of bird eggs. Auk 96:73-77.

Jasuja, R., P. Ramaraj, R. Phong Mac, A. B. Singh, T. W. Storer, J. Artaza, A. Miller, et al. 2005. $\Delta$-4-androstene-3,17-dione binds androgen receptor, promotes myogenesis in vitro, and increases serum testosterone levels, fat-free mass, and muscle strength in hypogonadal males. Journal of Clinical Endocrinology and Metabolism 90:855-863.

Johnson, A. L. 2000. Female reproduction. Pages 569-591 in G. C. Whittow, ed. Sturkie's avian physiology. 5th ed. Academic Press, San Diego, CA.

Ketterson, E. D., V. Nolan Jr., and M. Sandell. 2005. Testosterone in females: mediator of adaptive traits, constraint on sexual dimorphism, or both? American Naturalist 166(suppl.):S85-S98.
Lipar, J. L., E. D. Ketterson, and V. Nolan Jr. 1999. Intraclutch variation in testosterone content of red-winged blackbird eggs. Auk 116:231-235.

Martin, T. E. 1992. Breeding productivity considerations: what are the appropriate habitat features for management? Pages 455-473 in J. M. Hagan and D. W. Johnston, eds. Ecology and conservation of Neotropical migrants. Smithsonian Institution, Washington, DC.

. 1995. Avian life-history evolution in relation to nest sites, nest predation, and food. Ecological Monographs 65:101-127.

2002. A new view of avian life history tested on an incubation paradox. Proceedings of the Royal Society B: Biological Sciences 269:309-316.

Martin, T. E., J. Scott, and C. Menge. 2000. Nest predation increases with parental activity: separating nest site and parental activity effects. Proceedings of the Royal Society B: Biological Sciences 267: 2287-2294.

Martin, T. E., R. D. Bassar, S. K. Bassar, J. J. Fontaine, P. Lloyd, H. Mathewson, A. Niklison, and A. Chalfoun. 2006. Life history and ecological correlates of geographic variation in egg and clutch mass among passerine species. Evolution 60:390-398.

Mayfield, H. 1975. Suggestions for calculating nest success. Wilson Bulletin 87:456-466.

McCormick, C. M., B. F. Furey, M. Child, M. J. Sawyer, and S. M. Donohue. 1998. Neonatal sex hormones have "organizational" effects on the hypothalamic-pituitary-adrenal axis of male rats. Developmental Brain Research 105:295-307.

Metcalfe, N. B., and P. Monaghan. 2003. Growth versus lifespan: perspectives from evolutionary ecology. Experimental Gerontology 38:935-940.

Mousseau, T. A., and C. W. Fox. 1998. Maternal effects as adaptations. Oxford University Press, New York.

Müller, W., T. G. G. Groothuis, A. Kasprzik, C. Dijkstra, R. V. Alatalo, and H. Siitari. 2005. Prenatal androgen exposure modulates cellular and humoral immune function of black-headed gull chicks. Proceedings of the Royal Society B: Biological Sciences 272:19711977.

Navara, K. J., Hill, G. E., and M. T. Mendonça. 2005. Variable effects of yolk androgens on growth, survival, and immunity in eastern bluebird nestlings. Physiological and Biochemical Zoology 78:570578.

Payne, A. H., and D. B. Hales. 2004. Overview of steroidogenic enzymes in the pathway from cholesterol to active steroid hormones. Endocrine Reviews 25:947-970.

Pilz, K. M., H. G. Smith, M. I. Sandell, and H. Schwabl. 2003. Interfemale variation in egg yolk androgen allocation in the European starling: do high-quality females invest more? Animal Behaviour 65:841-850.

Poopatanapong, A. 2002. Relationship between male badge size and female reproductive investment and mate choice in house sparrow. MS thesis. Washington State University, Pullman.

Purvis, A., and A. Rambaut. 1995. Comparative analysis by independent contrast (CAIC): an Apple-Macintosh application for analyzing comparative data. Computer and Applied Biological Sciences 11:247-251.

Remeš, V., and T. E. Martin. 2002. Environmental influences on the evolution of growth and developmental rates in passerines. Evolution 56:2505-2518.

Romanoff, A. L. 1944. Avian spare yolk and its assimilation. Auk 61: 235-241. 
Schwabl, H. 1993. Yolk is a source of maternal testosterone for developing birds. Proceedings of the National Academy of Sciences of the USA 90:11439-11441.

- 1996. Maternal testosterone in the avian egg enhances postnatal growth. Comparative and Biochemical Physiology A 114: 271-276.

. 1997. Maternal steroid hormones in the egg. Pages 3-13 in R. Etches and S. Harvey, eds. Perspectives in avian endocrinology. Journal of Endocrinology, Bristol, UK.

. 1999. Developmental changes and among-sibling variation of corticosterone levels in an altricial avian species. General and Comparative Endocrinology 116:403-408.

Sibley, C. G., and J. E. Ahlquist. 1990. Phylogeny and classification of birds. Yale University Press, New Haven, CT.

Sockman, K. W., and H. Schwabl. 2000. Yolk androgens reduce offspring survival. Proceedings of the Royal Society B: Biological Sciences 267:1451-1456.

. 2001. Plasma corticosterone in nestling American kestrels: effects of age, handling stress, yolk androgens, and body condition. General and Comparative Endocrinology 122:205-212.

Sonneveld, E., H. J. Jansen, J. A. C. Riteco, A. Brouwer, and B. van der Burg. 2005. Development of androgen- and estrogen-response bioassays, members of a panel of human cell line-based highly selective steroid-responsive bioassays. Toxicological Sciences 83: 136-148.

Sonneveld, E., J. A. C. Riteco, H. J. Jansen, B. Pieterse, A. Brouwer, W. G. Schoonen, and B. van der Burg. 2006. Comparison of in vitro and in vivo screening models for androgenic and estrogenic activities. Toxicological Sciences 89:173-187.

Staub, N. L., and M. DeBeer. 1997. The role of androgens in female vertebrates. General and Comparative Endocrinology 108:1-24.

Strasser, R., and H. Schwabl. 2004. Yolk testosterone modifies the expression of sexually selected traits in sons. Behavioral Ecology and Sociobiology 56:491-497.

Tschirren, B., H. Richner, and H. Schwabl. 2004. Ectoparasite-modulated deposition of maternal androgens in great tit eggs. Proceedings of the Royal Society B: Biological Sciences. 271:13711375 .

Tschirren, B., V. Saladin, P. S. Fitze, H. Schwabl, and H. Richner. 2005. Maternal yolk testosterone does not modulate parasite susceptibility or immune function in great tit nestlings (Parus major). Journal of Animal Ecology 74:675-682.

von Engelhardt, N., C. Carere, C. Dijkstra, and T. G. G. Groothuis 2006. Sex-specific effects of yolk testosterone on survival, begging and growth of zebra finches. Proceedings of the Royal Society B: Biological Sciences 273:65-70.

Welberg, L. A. M., and J. R. Seckl. 2001. Prenatal stress, glucocorticoids and the programming of the brain. Journal of Neuroendocrinology 13:113-128.

Whittingham, L. A., and H. Schwabl. 2002. Maternal testosterone in tree swallow egg varies with female aggression. Animal Behaviour 63:63-67.

Associate Editor: Elizabeth Adkins-Regan Editor: Michael C. Whitlock 